10 Berisa F, McGonigle R, Beaman M, Adu D, Micheal J. The treatment of diabetic renal failure by continuous ambulatory peritoneal dialysis. Diabetic Med 1989;6:67-70

11 Kjellstrand CM, Whitley K, Comty CM, Shapiro FL. Dialysis in patients with diabetes mellitus. Diabetic Nephropathy 1983;2:5-17.

12 Brunner FP, Broyer M, Brynger H, et al. Survival on renal replacement therapy: data from the EDTA registry. Nephrol Dial Transplant 1988;2:109. 22.

13 Larsson O, Attman P, Aurell M, Frisk B, Brynger $\mathrm{H}$. Survival in end-stag diabetic renal disease. A prospective study of 100 kidney transplant patients. Acta Med Scand 1984;216:393-402.

14 Matson M, Kjellstrand CM. Long-term follow-up of 369 diabetic patients undergoing dialysis. Arch Intern Med 1988;148:600-4.

15 Grenfell A, Bewick M, Parsons V, Snowden S, Taube D, Watkins PJ. Noninsulin-dependent diabetes and renal replacement therapy. Diabetic Med 1988;5:172-6

16 Kaplan EL, Meier P. Non-parametric estimation from incomplete observations. Fournal of the American Statistical Association 1958;53:457-81.

17 Peto R, Pike MC, Armitage P, et al. Design and analysis of randomized clinical trials requiring prolonged observation of each patient. II. Analysis and examples. Br f Cancer 1977;35: 1-39.

18 Teutsch S, Newman J, Eggers $P$. The problem of diabetic renal failure in the United States: an overview. Am f Kidney Dis 1989;13:11-3.

19 Herman W, Hawthorne V, Hamman R, et al. Preventing the kidney disease of diabetes mellitus: public health perspectives. Consensus statement. $A m \mathcal{F}$ Kidnev Dis 1989:13:2-10.

20 Lynn KL, Frendin TJ, Walker RJ, Bailey RR, Swainson CP. Renal disease in diabetics - which patients have diabetic neophropathy and what is their outcome? Aust NZ F Med 1988;18:764-7.

21 Chihara J, Takebayashi S, Taguchi T, Yokoyama K, Harada T, Naito S Glomerulonephritis in diabetic patients and its effect on their prognosis. Nephron 1986;43:45-9.

22 Kasinath BS, Mujais SK, Spargo BH, Katz AI. Nondiabetic renal disease in patients with diabetes mellitus. Am $\mathcal{F}$. Med 1983;75:613-7.

23 Heaton A, Rodger RSC, Sellars L, et al. Continuous ambulatory peritoneal dialysis after the honeymoon: review of experience in Newcastle 1979-84 Br.Med f 1986;293:938-41.

24 Amair $\mathrm{P}$, Khanna R, Leibel B, et al. Continuous ambulatory peritoneal dialysis in diabetics with end-stage renal disease. $N$ Englf $M$ Med 1982;306:625-30.

25 Passlick J, Grabensee B. CAPD and transplantation in diabetics. Clin Nephrol 1988;30(suppl 1):S18-23.

26 Kraus S, Spector DA. Characteristics and sequelae of peritonitis in diabetics and nondiabetics receiving chronic intermittent peritoneal dialysis. Medicine 1983;62:52-7.

27 Manis T, Friedman EA. Current thinking on the management of the uremic diabetic. Semin Nephrol 1986;6:183-5.

28 Ghavamian M, Gutch CF, Kopp KF, Kolff WJ. The sad truth abou haemodialysis in diabetic nephropathy. FAMA 1972;222:1386-9.

29 Pyorala K, Laakso M. Macrovascular disease in diabetes mellitus. In: Mann JI, Pyorala K, Teuscher A, eds. Diabetes in epidemiological perspective. London: Churchill Livingstone, 1983:183-247.

Accepted 18 fune 1990)

\title{
Outcome of renal replacement treatment in patients with diabetes mellitus
}

\author{
Margaret A McMillan, J Douglas Briggs, Brian J R Junor
}

Abstract

Objective-To compare the outcome of renal replacement treatment in patients with diabetes mellitus and in non-diabetic patients with end stage renal failure.

Design-Retrospective comparison of cases and matched controls.

Setting - Renal unit, Western Infirmary, Glasgow, providing both dialysis and renal transplantation.

Patients-82 Diabetic patients starting renal replacement treatment between 1979 and 1988, compared with 82 matched non-diabetic controls with renal failure and 39 different matched controls undergoing renal transplantation.

Main outcome measures-Patient characteristics, history of smoking, prevalence of left ventricular hypertrophy and myocardial ischaemia at start of renal replacement treatment; survival of patients with renal replacement treatment and of patients and allografts with renal transplantation.

Results-The overall survival of the diabetic patients during the treatment was $83 \%, 59 \%$, and $50 \%$ at one, three, and five years. Survival was significantly poorer in the diabetic patients than the controls $(p<0 \cdot 001)$. Particularly adverse features for outcome at the start of treatment were increasing age $(\mathbf{p}<0.01$ ) and current cigarette smoking (relative risk ( $95 \%$ confidence interval) $2.28(0.93$ to 4.84$)$, $\mathrm{p}<0.05)$. Deaths were mainly from cardiac and vascular causes. The incidence of peritonitis in patients on continuous ambulatory peritoneal dialysis was the same in diabetic patients and controls $(49 \%$ in each group remained free of peritonitis after one year), and the survival of renal allografts was not significantly worse in diabetic patients $(p<0 \cdot 5)$.

Conclusions-Renal replacement treatment may give good results in diabetic patients, although the outlook remains less favourable than for non-diabetic patients because of coexistent, progressive vascular disease, which is more severe in older patients.

\section{Introduction}

The 10 years since this renal unit accepted its first diabetic patients for renal replacement treatment have seen the widespread introduction of continuous ambulatory peritoneal dialysis, increasingly successful renal transplantation, and relaxation of acceptance criteria for diabetic and non-diabetic patients with renal failure. ${ }^{12}$ Diabetic patients form an increasing proportion of the workload of most renal units in the United Kingdom. The percentage of all diabetic patients in the United Kingdom starting renal replacement treatment rose from $1.4 \%$ in $1974^{3}$ to $11.4 \%$ in $1985,{ }^{1}$ and that in this unit has now reached $20 \%$. Despite stringent selection of diabetic patients renal replacement treatment has been associated with poorer survival of diabetic than non-diabetic patients. ${ }^{3-5} \mathrm{We}$ know of no report in the United Kingdom of results of dialysis and transplantation in a less selected group, and we present such an analysis in diabetic and matched non-diabetic patients in the same renal unit.

\section{Patients and methods}

PATIENTS

All patients with end stage renal failure starting dialysis or undergoing renal transplantation at this hospital between 1 January 1979 and 31 December 1988 were considered. Clinical indications to start dialysis were symptoms of uraemia or intractable fluid overload. All patients with diabetes mellitus except two were included; one had renal impairment due to glomerulonephritis and the other impairment due to renal calculi.

\section{CONTROL GROUPS}

Non-diabetic renal replacement treatment group-One non-diabetic patient was selected as a control for each diabetic patient starting renal replacement treatment. The patients were matched for sex, year of starting the treatment, and type of dialysis. Within these constraints the control selected was the one whose date of birth was closest to that of the diabetic patient. This control group was used for all analyses except those of survival of patients and allografts after renal transplantation.

Non-diabetic transplant group-A separate control group was necessary to assess the results of renal transplantation, as the diabetic patients and matched 
controls starting renal replacement treatment were unlikely to receive a transplant within a similar period. One non-diabetic transplant recipient was selected as a control for each diabetic patient who received a transplant. The diabetic patients and controls were matched for sex, year of transplantation, and type of allograft (first or second cadaveric transplant or transplant from a live related donor), and the control selected was the one whose date of birth was closest to that of the diabetic patient. This control group was used for analyses of survival of patients and allografts after renal transplantation alone.

ANALYSES

All patients were followed up for a minimum of one year to December 1989. We analysed survival of patients with renal replacement treatment and survival of patients and allografts after transplantation. In view of changes in continuous ambulatory peritoneal dialysis techniques ${ }^{+}$during the study only patients using our current "disconnect" systems (Travenol $\mathrm{O}$ and $\mathrm{Y}$ systems, and Fresenius $5 \mathrm{~F}$ connector ${ }^{6}$ were included in the analysis of the incidence of peritonitis, which was defined by standard criteria. ${ }^{7}$ Case notes of diabetic patients and of the renal replacement treatment control group were examined retrospectively for history of smoking and electrocardiographic findings at the start of renal replacement treatment. Electrocardiograms were assessed with standard criteria ${ }^{8}$ for the presence of left ventricular hypertrophy and myocardial ischaemia. The presence or development of other vascular complications of diabetes was noted. Case-control data were analysed by McNemar's ${ }^{9}$ or Wilcoxon' ${ }^{10}$ tests for paired data. Unpaired data were analysed by the $\chi^{2}$ test $^{9}$ or Mann-Whitney U test. ${ }^{10}$ Data on survival were compiled by life table methods ${ }^{11}$ and analysed by log rank testing. ${ }^{11}$ The Cox model (biomedical programs data package 2L, Biomedical Programs Data Package Statistical Software) was used to test the association between clinical covariates at the start of renal replacement treatment and survival of the diabetic patients.

\section{Results}

Patient characteristics at the start of renal replacement treatment-Eighty two diabetic patients were studied (table I) matched with controls. Table II shows the causes of renal failure in the controls. Information on history of smoking was available for 75 patient-control pairs; 29 diabetic patients compared with 32 controls were current smokers, and only 32 patients compared with 28 controls were lifelong non-smokers. Resting electrocardiograms were available for 69 pairs (table III); the prevalence of left ventricular hypertrophy was similar in the diabetic patients and controls $54 \% v 57 \%$ respectively) but that of myocardial ischaemia was greater in the diabetic patients $(62 \% v 43 \%)$. Fifteen diabetic patients (but no controls) were blind, and all had retinopathy. Peripheral vascular insufficiency, defined as peripheral ischaemia with failure of skin healing, had affected 21 diabetic patients compared
TABLE II -Causes of renal failure in controls. Figures are numbers

\begin{tabular}{lcc}
\hline & $\begin{array}{c}\text { Renal replacement } \\
\text { treatment } \\
\text { control group }\end{array}$ & $\begin{array}{c}\text { Transplant } \\
\text { control } \\
\text { group }\end{array}$ \\
\hline Glomerulonephritis & 35 & 19 \\
Pyelonephritis & 12 & 8 \\
Polycystic kidney disease & 10 & 6 \\
Hypertensive nephrosclerosis & 8 & 2 \\
$\begin{array}{l}\text { Obstructive uropathy } \\
\text { Analgesic nephropathy }\end{array}$ & 5 & 3 \\
$\begin{array}{l}\text { Multisystem disease (systemic } \\
\text { lupus erythematosus, }\end{array}$ & 4 & 1 \\
amyloidosis, gout, vasculitis) & & \\
\hline
\end{tabular}

TABLE III-Prevalance of myocardial ischaemia at start of renal replacement treatment in 69 diabetic patient-control pairs

\begin{tabular}{lcc}
\hline & \multicolumn{2}{c}{ Diabetic patients } \\
\cline { 2 - 3 } Controls & Ischaemia & No ischaemia \\
\hline Ischaemia & 23 & 7 \\
No ischaemia & 20 & 19 \\
\hline
\end{tabular}

Diabetics $>$ controls, McNemar's test, $\mathrm{p}<0.025$.

TABLE IV-Survival during renal replacement treatment of 82 diabeticcontrol pairs

\begin{tabular}{lccc}
\hline & \multicolumn{3}{c}{ No of pairs with completed follow up } \\
\cline { 2 - 4 } Surviving patients & 1 Year & 3 Years & 5 Years \\
\hline Diabetic patients and controls & 64 & 30 & 20 \\
Diabetic patients only & 3 & 2 & 0 \\
Controls only & 12 & 20 & 14 \\
Neither & 3 & 5 & 2 \\
\hline Diabetics<controls, & & & \\
$\quad$ McNemar's test & $\mathrm{p}<0.05$ & $\mathrm{p}<0.001$ & $\mathrm{p}<0.001$ \\
& & &
\end{tabular}

with no controls and was significantly more common in the patients with non-insulin dependent diabetes mellitus than insulin dependent diabetes mellitus $\left(11 / 21,52 \%\right.$ v 10/61, 16\%; $\chi^{2}$ test, $\left.\mathrm{p}<0 \cdot 01\right)$. Ten diabetic patients compared with two controls had a history of cerebrovascular accident or transient cerebral ischaemia.

Survival with renal replacement treatment-Fig 1 shows survival curves for the diabetic patients and matched controls, calculated from the date of starting renal replacement treatment. Survival was significantly poorer in the diabetic patients than in the corresponding controls (log rank test, patients with insulin dependent diabetes mellitus $v$ controls, $\mathrm{p}<0.01$; patients with non-insulin dependent diabetes mellitus $v$ controls, $\mathrm{p}<0.001$; patients with insulin dependent $v$ patients with non-insulin dependent diabetes mellitus, $\mathrm{p}<0.001)$. Table IV compares survival of patientcontrol pairs; table $\mathrm{V}$ shows causes of death. Cardiac and other vascular disease accounted for $88 \%$ of the deaths of the diabetic patients compared with $54 \%$ of controls $\left(\chi^{2}\right.$ test, $\left.\mathrm{p}<0 \cdot 01\right)$. Analysis of survival by Cox's proportional hazards model with eight chosen covariates (table VI) gave a global $\chi^{2}$ value of $31 \cdot 3$ $(p<0.001)$. All the covariates apart from age were

TABLE I-Characteristics of diabetic and control groups on starting renal replacement treatment

\begin{tabular}{|c|c|c|c|c|c|}
\hline & \multicolumn{2}{|c|}{ Diabetic patients } & \multicolumn{2}{|c|}{ Controls } & \multirow[b]{2}{*}{ p Value } \\
\hline & $\begin{array}{c}\text { Insulin dependent } \\
\text { diabetes mellitus }\end{array}$ & $\begin{array}{l}\text { Non-insulin dependent } \\
\text { diabetes mellitus }\end{array}$ & $\begin{array}{l}\text { Insulin dependent } \\
\text { diabetes mellitus }\end{array}$ & $\begin{array}{l}\text { Non-insulin dependent } \\
\text { diabetes mellitus }\end{array}$ & \\
\hline No of patients (men) & $61(40)$ & $21(14)$ & $61(40)$ & $21(14)$ & \\
\hline Mean (range) age (years) & $40(21-66)$ & $58(20-66)$ & $41(46-72)$ & $57(46-71)$ & $<0.001^{\star}$ \\
\hline Mean (range) duration of diabetes (years) & $22(12-40)$ & $12(3-31)$ & & & $<0.001 \dagger$ \\
\hline Median (range) serum creatinine $(\mu \mathrm{mol} / \mathrm{l})$ & $1079(459-1753)$ & $1016(753-1375)$ & $1186(631-1887)$ & $1052(698-1425)$ & $<0.01 \ddagger$ \\
\hline Median (range) follow up of treatment (months) & $56(12-132)$ & $45(13-127)$ & $57(14-24)$ & $49(17-131)$ & \\
\hline
\end{tabular}

$\star$ Insulin dependent diabetes mellitus $<$ non-insulin dependent diabetes mellitus, Mann-Whitney U test.

tInsulin dependent diabetes mellitus $>$ non-insulin dependent diabetes mellitus, Mann-Whitney U test.

$\ddagger$ Diabetic patients < controls, Wilcoxon test. 
dichotomous; table VI shows the relative risks associated with their presence at the start of renal replacement treatment. The only significantly adverse factors were increasing age (coefficient 0.061 (SE $0.020), p<0.01$ ) and, to a lesser extent, current smoking $(\mathrm{p}<0.05)$. Compared with a patient 10 years younger, a patient aged between 50 and 60 at the start of the treatment had a relative risk $(95 \%$ confidence interval) of death within one year of $2.65(0.45$ to $15.49)$ and within three years of $2.25(0.55$ to 9.21$)$. Only one of 14 patients aged under 30 , but 5 of 11 patients aged over 60 , died within one year.

Results of continuous ambulatory peritoneal dialysisSeventy six of the 82 diabetic patients started continuous ambulatory peritoneal dialysis, rather than haemodialysis. Since our transfer to disconnect systems only one diabetic patient was withdrawn from this treatment because of peritonitis. The cumulative percentage of patients remaining free of peritonitis one year after starting treatment was $49 \%$ in both the diabetic patients and controls.

Progression of diabetic complications during renal replacement treatment-Diabetic complications other than nephropathy continued to develop in patients having all types of renal replacement treatment, including those with successful renal transplants. Despite regular ophthalmic review nine further diabetic patients became blind. Fifteen diabetic patients

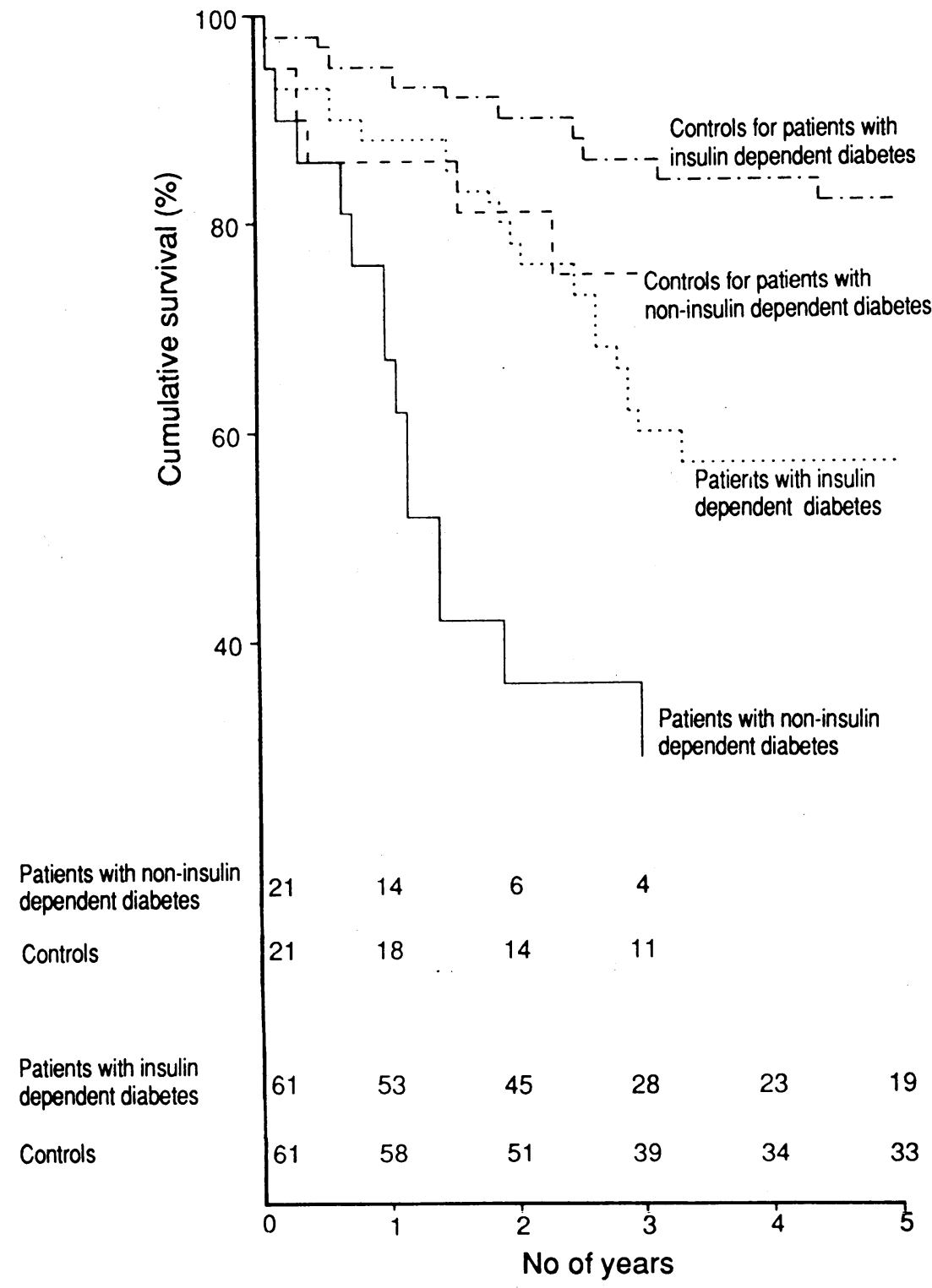

FIG 1-Surival of diabetic patients and matched controls during renal, replacement treatment
TABLE V-Causes of death in diabetic patients and controls. Figures are numbers of patients

\begin{tabular}{lcc}
\hline & Diabetic patients & Controls \\
\hline Cardiac & 21 & 11 \\
Cerebrovascular & 9 & 2 \\
Peripheral vascular & 6 & 1 \\
Sepsis & 2 & 3 \\
Other & 3 & 9 \\
\hline Total & 41 & 26
\end{tabular}

TABLE VI - Relative risk of death ( $95 \%$ confidence interval) in diabetic patients according to clinical covariates at start of renal replacement treatment

\begin{tabular}{ll}
\hline Covariate & \\
\hline Age & (Continuous variable $) \mathrm{p}<0.01$ \\
Current smoker & $2 \cdot 28(0.93$ to 4.84$) \mathrm{p}<0.05$ \\
Peripheral vascular insufficiency & $1 \cdot 72(0.75$ to 3.93$)$ \\
Female & $1.05(0.53$ to 2.06$)$ \\
Left ventricular hypertrophy & $0.95(0.44$ to 2.03$)$ \\
Myocardial ischaemia & $0.86(0.35$ to 2.09$)$ \\
Insulin treatment & $0.61(0.29$ to 1.27$)$ \\
Blindness & $0.57(0.22$ to 1.47$)$
\end{tabular}

TABLE VII-Characteristics of 39 diabetic patients receiving 41 renal transplants

\begin{tabular}{ll}
\hline Characteristic & \\
\hline Mean (range) age (years) & $39(22-62)$ \\
Ratio men:women & $27: 12$ \\
Ratio insulin dependent diabetes mellitus:non-insulin & $38: 1$ \\
$\quad$ dependent diabetes mellitus & $54(12-117)$ \\
Median (range) follow up (months) & 3 \\
Type of allograft: & 36 \\
First live related donor & 2 \\
First cadaveric donor & \\
\hline
\end{tabular}

TABLE VIII-Patients and allografts in diabetic-control pairs with follow up at one year and three years. Figures are numbers of pairs

\begin{tabular}{lrrrrrr}
\hline & \multicolumn{2}{c}{ Patients } & & \multicolumn{2}{c}{ Allografts } \\
\cline { 2 - 3 } \cline { 6 - 7 } Survivors & 1 Year & 3 Years & & 1 Year & 3 Years \\
\hline Diabetic patients & 35 & 21 & & 27 & 12 \\
Diabetic patients and controls only & 0 & 1 & & 4 & 7 \\
Controls only & 4 & 7 & & 8 & 9 \\
Neither & 0 & 1 & & 2 & 4
\end{tabular}

Diabetic $<$ controls, McNemar's test $\quad \mathrm{p}<0.20 \mathrm{p}<0.10 \quad \mathrm{p}<0.50 \mathrm{p}<0.90$

compared with one control developed peripheral vascular insufficiency. Nine of the surviving diabetic patients and two controls developed symptoms of cerebrovascular disease, and seven patients and one control had acute myocardial infarctions.

Results of renal transplantation-By 31 December 1988,41 renal transplants had been performed in 39 diabetic patients (table VII). Table II shows the causes of renal failure in their matched controls. The protocols for tissue matching and immunosuppressive treatment were the same for both groups. To assess survival each patient was considered from the date of the first transplant (39 patients/group); for survival of allografts all transplants were included (41 transplants/group). Fig 2 shows overall survival of patients and allografts, and table VIII survival of matched pairs. The results for survival of allografts were similar in diabetic patients and controls. More diabetic patients than controls died, but the difference in survival was of borderline significance (fig $2, \log$ rank test $\chi^{2}=3.90$, $\mathrm{p}<0.05$; table VIII, McNemar's test at three years' survival, $\left.\chi^{2}=3 \cdot 12,0.05<p<0 \cdot 10\right)$. Of the 21 patients (13 diabetic, 8 control) who died, 13 had failing grafts or had resumed dialysis, but immunosuppressive treatment contributed directly to death in only one (diabetic) patient. Two transplants in the controls were 


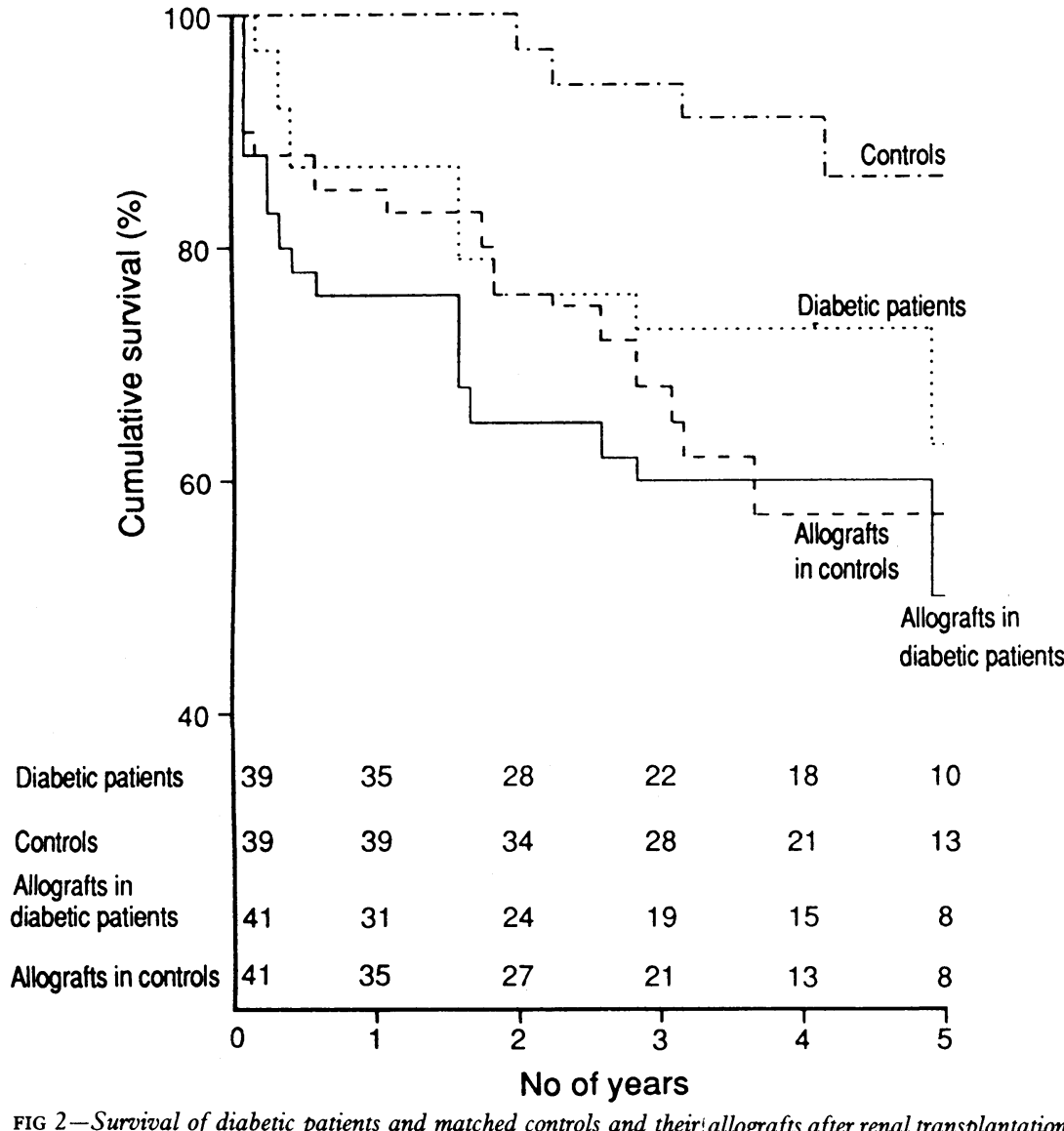

FIG 2-Survival of diabetic patients and matched controls and theiriallografts after renal transplantation

TABLE IX-Biochemical measures at 31 December 1989 in diabetic patients and controls with functioning renal allografts

\begin{tabular}{lcc}
\hline & $\begin{array}{c}\text { Diabetic patients } \\
(\mathrm{n}=23)\end{array}$ & $\begin{array}{c}\text { Controls } \\
(\mathrm{n}=24)\end{array}$ \\
\hline $\begin{array}{l}\text { Median (range) serum creatinine } \\
(\mu \mathrm{mol} / \mathrm{l})\end{array}$ & $111(68-318)$ & $117(72-437)$ \\
$\begin{array}{c}\text { Median serum (range) creatinine } \\
(\mu \mathrm{mol} / \mathrm{l}) \text { in 14 patient pairs with } \\
\text { functioning allografts }\end{array}$ & $114(83-318)$ & $113(82-252)$ \\
$\begin{array}{l}\text { No of patients with proteinuria } \\
>1 \mathrm{~g} / 24 \mathrm{~h}\end{array}$ & 1 & 2 \\
\hline
\end{tabular}

lost because of recurrent glomerulonephritis. No transplant was lost because of recurrence of diabetic nephropathy. Control of blood pressure was comparable in the diabetic and control patients with functioning transplants. Table IX shows biochemical data for these patients.

\section{Discussion}

As many as $20 \%$ of patients starting renal replacement treatment in our renal unit have diabetes. The intake to renal replacement treatment in the west of Scotland in 1988 was 56 patients per million population. If the incidence of end stage renal failure due to diabetic nephropathy in the United Kingdom has been correctly estimated at 10 patients per million population per year ${ }^{12}$ our diabetic population seems to be selected no more than our other patients with renal failure. Yet survival of these relatively unselected patients with renal replacement treatment was no worse than previous reports of more selected patients. ${ }^{131314}$ Although survival was better in our patients with insulin dependent than with non-insulin dependent diabetes mellitus (fig 1), this seemed to be related mainly to their younger age (tables I, VI). We did not attempt to assess the relative contributions to survival of the different forms of renal replacement treatment. Continuous ambulatory peritoneal dialysis is widely assumed to be preferable to haemodialysis for diabetic patients, ${ }^{7}$ and almost all our diabetic patients started with this treatment. It is now the form of dialysis chosen by $80 \%$ of our patients, with or without diabetes, so our comparative survival data are unlikely to be affected by selection bias in our control group starting continuous ambulatory peritoneal dialysis.

The causes of death recorded in the study (table V) reflect the high cardiovascular mortality in patients receiving renal replacement treatment ${ }^{2}$ and in the population of the west of Scotland..$^{15}$ As in other European centres ${ }^{1216}$ the excess deaths in our diabetic patients were due to vascular disease, which was present before renal replacement treatment and subsequently progressed. Diabetic patients with proteinuria are estimated to have a relative mortality from cardiovascular disease of 37 times that of the general population. ${ }^{17}$ There are reports also in these patients of aggregation of other risk factors for atherosclerosis, such as hypertension, ${ }^{18} 19$ lipid abnormalities, ${ }^{18}$ and smoking. ${ }^{20}$ Electrocardiographic evidence of hypertension was common in both our diabetic patients and controls. We did not routinely check plasma lipid concentrations. Smoking habits in our group were similar, and in keeping with reported prevalence for Glasgow. ${ }^{15}$ The association between continued smoking and death with renal replacement treatment (table VI) may reflect accelerated vascular disease or a general failure to comply with medical advice.

Most reports show an increased incidence of peritonitis in diabetic patients during continuous ambulatory dialysis. ${ }^{47}$ One possible explanation for our contrasting result is our choice of subcutaneous insulin as a result of our impression that intraperitoneal insulin led to an increased rate of peritonitis in patients using a disconnect system. ${ }^{6}$

There are numerous reports of a poorer outcome of renal transplantation in diabetic patients..$^{21}$ Survival of the allograft was similar in our diabetic patients and controls; survival of the diabetic patients seemed poorer (fig 2), although in analysis of matched pairs the difference failed to reach significance (table VIII). We have not yet lost a transplant because of recurrent diabetic nephropathy, but two cases of such loss more than 12 years after transplantation have been reported. ${ }^{22}$

In conclusion, we have shown that an integrated programme of dialysis and transplantation may yield good results in younger diabetic patients with renal failure. The prognosis for older patients is less good, mainly because of progressive vascular disease.

We thank Dr Adrian Bowman, department of statistics, University of Glasgow, for statistical advice, and Dr Kate Howie, department of materia medica, University of Glasgow, for her help with computing.

1 Brunner FP, Brynger H, Challah S, et al. Renal replacement therapy in patients with diabetic nephropathy 1980-1985: report from the Europea Dialysis and Transplant Association Registry. Nephrol Dial Transplan 1983;3:585-95

2 Brunner FP, Fassbinder W, Broyer M, et al. Combined report on regula dialysis and transplantation in Europe, XVIII. London: Springer-Verlag, 1989.

3 Cameron JS, Challah S. Treatment of end-stage renal failure due to diabetes in the United Kingdom, 1975-84. Lancet 1986;ii:962-6.

4 Gokal R, Jakubowski C, King J, et al. Outcome in patients on continuous ambulatory peritoneal dialysis: 4-year analysis of a prospective multicentre study. Lancet 1987;ii: 1105-9.

5 Brunner FP, Broyer $\mathrm{M}$, Brynger $\mathrm{H}$, et al. Survival on renal replacement therapy: data from the EDTA Registry. Nephrol Dial Transplant 1983;3: therapy:

6 Junor BJR. CAPD disconnect systems. Blood Purif 1989;7:156-66.

7 Nolph K, Lindblad AS, Novak JW. Continuous ambulatory peritoneal dialysis. N Engl f Med 1988;318:1595-9.

8 Schamroth L. An introduction to electrocardiography. Oxford: Blackwell, 1976.

9 Armitage P, Berry G. Statistical inference. In: Statistical methods in medical research. 2nd ed. Oxford: Blackwell, 1987:93-140.

10 Armitage P, Berry G. Distribution-free methods. In: Statistical methods in medical research. 2nd ed. Oxford: Blackwell, 1987:408-20.

11 Armitage P, Berry G. Survival analysis. In: Statistical methods in medical research. 2nd ed. Oxford: Blackwell, 1987:421-39. 
12 Joint Working Party on Diabetic Renal Failure of the British Diabetic Association, the Renal Association, and the Research Unit of the Royal College of Physicians. Treatment of and mortality from diabetic renal failure in patients identified in the 1985 United Kingdom survey. $\mathrm{Br}$ Med $\mathcal{F}$ 1989;299:1135-6.

13 Burton PR, Walls J. Selection-adjusted comparisons of life expectancy of patients on continuous ambulatory peritoneal dialysis, haemodialysis and renal transplantation. Lancet 1987 ; i: 1118-9.

14 Paterson AD, Dornan TL, Peacock I, et al. Causes of death in diabetic patients with impaired renal function. Lancet $1987 ; \mathrm{i}: 313-6$.

15 Mann JI, Lewis B, Shepherd J, et al. Blood lipid concentrations and other cardiovascular risk factors: distribution, prevalence, and detection in Britain. Br Med f 1988;296: 1702-6.

16 Rottembourg J, Issad B, Allouache $M$, et al. Clinical aspects of continuous ambulatory and continuous cyclic peritoneal dialysis in diabetic patients. Peritoneal Dialysis International 1989;9:289-94.

17 Borch-Johnsen K, Kreiner S. Proteinuria: value as predictor of cardiovascula mortality in insulin dependent diabetes mellitus. Br Med f 1987;294:1651-4.
18 Winocour PH, Durrington PN, Ishola M, et al. Influence of proteinuria on vascular disease, blood pressure, and lipoproteins in insulin dependen diabetes mellitus. $\mathrm{Br}$ Med $\mathcal{F}$ 1987;294:1648-51.

19 Parving HH, Hommel E, Mathiesen E, et al. Prevalence of microalbuminuria aterial hypertension, retinopathy, and neuropathy in patients with insulin dependent diabetes. $\mathrm{Br} \mathrm{Med} \mathcal{F}$ 1988;296:156-60.

20 Mulhauser I, Sawicki P, Berger M. Cigarette smoking as a risk factor for macroproteinuria and proliferative retinopathy in Type 1 (insulindependent) diabetes. Diabetologia 1986;29:500-2.

21 Tilney NL. The juvenile onset diabetic in renal failure. In: Morris PJ Tilney NL, eds. Progress in transplantation. Vol 2. Edinburgh: Churchill Livingstone, 1985:106-23.

22 Najarian JS, Kaufman DB, Fryd DS, et al. Long-term survival following kidney transplantation in 100 type 1 diabetic patients. Transplantation kidney transplan
$1989 ; 47: 106-13$.

(Accepted 12 fuly 1990)

\section{ANY QUESTIONS}

\begin{abstract}
Is there any radiation emitted by a modern colour television and, if so, how close can children sit to a set without fear of damaging exposure?
\end{abstract}

In the early days of colour televisions there was some worry over the emission of $x$ rays from the cathode ray tube and thermionic valves. But with a suitable thickness of glass in front of the cathode ray tube and the use of modern electronics $x$ ray emissions are negligible. Most of the measurements on emissions from cathode ray tube display units in recent years have been carried out on visual display units attached to computers, where the operator may sit quite close to the screen for up to eight hours a day. We have carried out several measurements on different designs of computer terminals and found no detectable emissions of $x$ rays. The glass used on the front of the screens, however, is naturally but slightly radioactive, as is the glass in domestic television sets and windows. ${ }^{\text {T }}$ The radiation comes from naturally occurring potassium- 40 , which is also found in humans. The dose level, even in contact with the glass of the television set, is small and comparable with that occurring naturally from another person.

Colour televisions, along with computer monitors, emit non-ionising radiations. These come from the mains $(50 \mathrm{~Hz})$ and flyback $(10-30 \mathrm{kHz})$ transformers in the television set.

The field strengths measured at $30 \mathrm{~cm}$ from a 27 inch $(69 \mathrm{~cm})$ colour television screen are fractions of those recommended as safe by the National Radiological Protection Board. ${ }^{2}$ The field strengths fall approximately as a function of the cube of the distance as you move away from the screen. We suggest that the safe distance for viewing the television screen will be related to comfort rather than to any restrictions due to radiation emitted. - I B O'HAGAN, senior scientific officer, and A S TAYLOR, scientific officer, National Radiological Protection Board, Chilton, Didcot, Oxfordshire

1 Driscoll CMH, Burgess PH, Harlen F, Richards DJ. Measurements to detect ionising radiation in the vicinity of monochromatic visual display units. National Radiological Protection Board the vicinity of monochromatic visual display unis.

2 National Radiological Protection Board. Guidance on standards. Guidance as to restrictions on exposures to time varying electromagnetic fields and the 1988 recommendations of the international non-ionizing radiation committee NRPB-GS11. Didcot: NRPB, 1989.

What practical advice can I give a patient with Sjögren's syndrome who suffers badly at night-waking with a dry mouth and a feeling of dryness of the upper chest?

Patients with Sjögren's syndrome suffer from dry eyes (keratoconjunctivitis sicca) and dry mouth (xerostomia) and may also have vaginal dryness. Treatment is essentially symptomatic with artificial tears (usually methylcellulose), frequent drinking of water, and stimulation of salivation by chewing gums (non-sucrose), diabetic confectionery, or citrus fruits, and use of a suitable vaginal lubricant. This patient's problem of waking during sleep with a dry mouth and chest which is eventually relieved by drinking water suggests that the dryness is oropharyngeal and perhaps oesophageal. Reduction of alcohol consumption and smoking should be advised if appropriate and oral candidiasis treated if present. Artificial saliva taken just before bedtime may help and this may need to be repeated once during the night. Various proprietary preparations are available but artificial saliva, which can be made up by a pharmacist, may be more useful in this patient as it could be diluted to enable a larger volume to be administered. Various sialagogues (pyridostigmine, ${ }^{1}$ pilocarpine) and mucolytics (acetylcysteine, ambroxol ${ }^{2}$ ) have been tried with limited success and their side effects do not justify their routine use, although they could be tried in severe cases of xerostomia. Less commonly a dry throat and chest may be caused by dryness of the respiratory tract (xerotrachea), particularly if the patient has a persistent dry cough. If the above measures fail it may be worth trying steam inhalations before sleep or even a portable air humidifier during sleep, although the expense and inconvenience of this would probably outweigh any benefit to the patient. - A S VATHENEN, senior registrar in respiratory and general medicine, Leeds

1 Navazesh M, Ship II. Xerostomia: diagnosis and treatment. Am $\mathcal{f}$ Otolaryngol 1983;4: 283-92.

2 Ichikawa $\mathrm{Y}$, Tokunaga $M$, Shimizu $\mathrm{H}$, Moriuchi J, Takaya $M$, Arimori S. Clinical trial of ambroxol (Mucosolvan) in Siogren's syndrome. Tokai f Exp Clin Med 1988;13:165-9.

\section{Why do some people tolerate white wine better than red wine?}

Red wine and white wine do not differ in alcohol content. Red wine is known to precipitate migraine in some patients and this has been attributed to the presence of tyramine. Recent studies, however, have shown that red wine and white do not differ in their content of tyramine. ${ }^{12}$ The main difference between the two is their content of phenolic flavanoids. These are leached out from the grape skin and pips during fermentation and give red wine its colour. Red wine may contain up to $1200 \mathrm{mg} / \mathrm{l}$ of these substances whereas white wine has only about $50 \mathrm{mg} / \mathrm{l}$. It seems likely that this is the reason why some people tolerate white wine better than red but the mechanism is not established. The fact that flavanoids act as inhibitors of enzymes that break down catecholamine and other amines such as tyramine may be relevant. - LINDA BEELEY, consultant clinical pharmacologist, Birmingham

1 Littlewood JT, Gibb C, Glover V, Sandler M, Davies PTG, Rose F. Red wine as a cause of migraine. Lancet 1988 ;i:558-9.

2 Hannah P, Glover V, Sandler M. Tyramine in wine and beer. Lancet 1988;i:879.

Is there any benefit in combining aspirin and paracetamol in the treatment of viral pharyngitis or flu?

There are several theoretical reasons why combining these two analgesics might be useful. Firstly, although both drugs are cyclo-oxygenase inhibitors, their mode of action is not identical. Aspirin has a greater peripheral anti-inflammatory effect than paracetamol, which is thought to act mainly centrally. I do not know if these differences are of any clinical relevance. Secondly, combining the two drugs is a way of increasing the total dose without increasing the dose of either drug. Paracetamol has a flat dose-response relation with little increase in effect at doses greater than $1 \cdot 0-1 \cdot 5 \mathrm{~g}$. The analgesic effect of aspirin can be increased by increasing the dose, but the risk of adverse effects, especially gastric bleeding, is also increased. I do not know if combining the drugs in practice does in fact increase the analgesic effect or how it compares with doubling the dose of aspirin alone. Thirdly, there is evidence that simultaneous administration of paracetamol and aspirin results in higher blood concentrations of aspirin than the same dose of aspirin given alone. Again the clinical importance of this is unknown, but it could be a way of increasing the analgesic effect of aspirin without increasing the risk of gastric bleeding. There is, of course, a precedent for using the combination in benorylate, a prodrug that is metabolised to aspirin and paracetamol after absorption. - LINDA BEELEY, director, drug and therapeutics unit, Birmingham

Cotty VF, Sterbenz FT, Mueller F, et al. Augmentation of human blood acetysalicylate concentration by the simultaneous administration of acetaminophen with aspirin. Toxicol Appl Pharmacol 1977;41:7-13. 